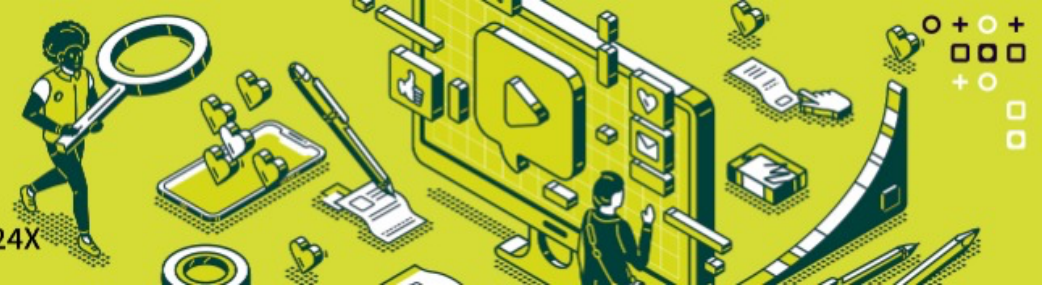

\title{
ENSINO REMOTO PARA ELABORAÇÃO DE TRABALHO FINAL DE CURSO: EXPERIÊNCIA DE ATIVIDADE DE EXTENSÃO UNIVERSITÁRIA
}

\section{REMOTE TEACHING FOR FINAL COURSE WORK: EXPERIENCE OF UNIVERSITY EXTENSION ACTIVITY}

Bonatto, Eyde Cristianne Saraiva ${ }^{1}$, Bonatto, Jhonny de Araújo ${ }^{2}$

\author{
${ }^{1}$ Universidade Federal do Amazonas- eydesaraiva@ufam.edu.br \\ ²Universidade Federal do Amazonas- jhonnybonatto@hotmail.com
}

\begin{abstract}
Resumo: Na educação acadêmica o contato do docente com o discente é fundamental no processo de ensino-aprendizagem. Entretanto, o novo coronavírus nos impeliu a mudar nosso comportamento social e adotar novos hábitos no enfretamento ao COVID-19. O distanciamento social foi ampliado principalmente para o segmento educacional, e as tecnologias da informação e comunicação (TIC's) se tornaram alternativas para que o ensino e a pesquisa acadêmica fossem continuados. $O$ objetivo da pesquisa foi descrever a experiência na ministração de curso para confecção de trabalho de conclusão de curso em conformidade com as normas da ABNT de forma remota, como ação de extensão universitária. A pesquisa baseou-se na pesquisa quali-quantitativa alinhada ao "Curso teórico-prático para elaboração de Trabalho Conclusão de Curso -TCC", desenvolvido no âmbito do Programa de Ação Curricular Remota de Extensão Emergencial. Os participantes dos cursos estavam matriculados em 15 instituição de ensino superior e uma de pesquisa. Os alunos em graduação totalizaram $83 \%$ e os de pós-graduação, $17 \%$. 0 sexo feminino foi predominante (59\%). As instituições de ensino superior, que os participantes estavam vinculados, pertenciam as regiões norte (81\%), nordeste $(13 \%)$ e sudeste (6\%). Assim, o ensino remoto associado as TIC's, material didático bom e o acesso à internet, podem contribuir de sobremaneira para continuidade do ensino e aprendizagem, inclusive por meio de ações de extensão universitária.
\end{abstract}

Palavras-chave: educação, normas técnicas, práticas extensionistas

\begin{abstract}
In academic education, the contact between the teacher and the student is essential in the teaching-learning process. However, the new coronavirus urged us to change our social behavior and adopt new habits in dealing with COVID-19. Social distancing was mainly extended to the educational segment, and information and communication technologies (ICT's) became alternatives so that teaching and academic research could be continued. The objective of the research was to describe the experience in providing a course for the preparation of a course conclusion work in accordance with the norms of the ABNT remotely, as a university extension action. The research was based on qualitative-quantitative aligned with the "Theoretical-practical course for the elaboration of Course Conclusion Work TCC", developed within the scope of the Emergency Extension Remote Curriculum Action Program. Course participants were enrolled in 15 higher education institutions and one research institution. Undergraduate students totaled $83 \%$ and graduate students $17 \%$. Females were predominant (59\%). The higher education institutions to which the participants were linked belonged to the North $(81 \%)$, Northeast (13\%) and Southeast (6\%) regions. Thus, remote teaching associated with ICT's, good teaching material and internet access, can greatly contribute to the continuity of teaching and learning, including through university extension actions.
\end{abstract}

Keywords: education, technical standards, extension practices. 


\section{INTRODUÇÃO}

Na educação acadêmica o contato do docente com o discente é fundamental no processo de ensinoaprendizagem. Entretanto, o novo coronavírus nos impeliu a mudar nosso comportamento social e adotar novos hábitos no enfretamento ao COVID-19. Logo, o distanciamento social constitui-se em uma das medidas orientadas pelo Ministério da Saúde, e visa a redução do número de infecções em determinado período de tempo, em função da menor transmissão da doença entre a população.

Assim, as tecnologias da informação e comunicação ( $\left.T I C^{\prime} s\right)$ são alternativas para que o ensino e a pesquisa acadêmica sejam continuados. Nesse contexto, os trabalhos finais de curso (TCC's) são indispensáveis para que o discente seja exitoso na conclusão do curso de graduação, assim como o devido repasse de conhecimento que emprega o estudo, análise, teoria, e as atividades práticas, para consolidação do conhecimento.

E junto ao processo de construção de conhecimentos, também se observa uma constante mudança social. Essa é a grande contribuição que a pesquisa agrega ao estudante, a possibilidade de impactar na sociedade e promover mudanças (TRINDADE, BACHUR e OLIVEIRA, 2018).

O enfoque analítico, destarte, situa a extensão universitária e as interações na comunidade. Uma universidade atuante (viva), deve, logo, agir em prol de enredos de inovação social e comunitária. Ao pesquisar a interligação da produção de conhecimento de uma universidade e a transferência dessa informação para a sociedade, observa-se a atuação da extensão universitária. Busca-se, então responder à seguinte provocação: em quais projetos, atualmente, a extensão da Universidade pública federal (Ufes) tem-se direcionado ao 'combate' à pandemia do novo coronavírus? (MIGUEL, SILVEIRA e DEL MAESTRO, 2021).

No estudo realizado por Melo et al. (2021), reponde a pergunta supra citada, a saber:

[...] $87,5 \%$ das IES públicas optaram por continuar as ações de extensão durante 2020, com $87,9 \%$ sendo adaptadas e $71,8 \%$ com flexibilização das normas. As modalidades extensionistas, tais como projetos (90,3\%), programas $(75 \%)$, cursos $(78,2 \%)$ e eventos (75\%), foram expressivamente realizadas. Todavia, apenas $51 \%$ das IES apresentaram prestação de serviços. Ações destinadas ao enfrentamento da COVID-19 envolveram disponibilização de informações (34\%), confecção/entrega de materiais destinados a prevenção (12\%) e realização de atendimento aos casos (4\%). $24 \%$ das instituições publicaram edital de extensão com vigência para 2021 com adequações à pandemia, enquanto $38 \%$ publicaram edital sem adequações. Concluise que a extensão foi adaptada às necessidades desencadeadas pela pandemia da COVID-19 e ações de enfrentamento foram desenvolvidas para amenizar o cenário pandêmico (MELO et al., 2021).

A Universidade Federal do Amazonas, publicou edital, nos anos de 2020 e 2021, com adequação referente ao combate do coronavírus, possibilitando a realização de projeto de forma remota.

Frente ao exposto, o objetivo da pesquisa foi descrever a experiência na ministração de curso para confecção de trabalho de conclusão de curso em conformidade com as normas da Associação de Normas Técnicas Brasileiras (ABNT) de forma remota, como ação de extensão universitária durante a pandemia do coronavírus. 


\section{Metodologia}

A pesquisa em tela baseou-se na pesquisa quali-quantitativa alinhada ao "Curso teórico-prático para elaboração de Trabalho Conclusão de Curso -TCC", desenvolvido no âmbito do Programa de Ação Curricular Remota de Extensão (Pace Emergencial).

O curso orientativo foi baseado nas normas técnicas para o trabalho científico, descritas pela Associação Brasileira de Normas Técnicas. Concentrando-se nos três elementos textuais essências que de acordo com Furasté (2012), quais sejam:

a) Elementos pré-textuais: são aqueles que antecedem o corpo do trabalho, propriamente dito, com informações que ajudam na identificação, finalidade e utilização do trabalho;

b) Elementos textuais: trata-se do corpo do trabalho, onde se faz a exposição da matéria tratada na pesquisa realizada (introdução, desenvolvimento e conclusão);

c) Elementos pós-textuais, aqueles que complementam o trabalho e aparecem após o corpo propriamente dito.

As inscrições e emissão de certificados foram feitas via portal do EVEN3@) o link de inscrição foi divulgado nas redes sociais.

O curso foi ministrado de forma remota via sala de aula virtual construída na plataforma Google Classroom (․ As aulas foram desenvolvidas de forma assíncrona e síncrona. Como material didático, foi disponibilizada uma apostila digital com os conteúdos ministrados. Também foram apresentados exercícios para fixação do conteúdo ministrado, os quais compõem o conteúdo da apostila digital.

O curso foi ministrado de forma remota síncrona realizadas pelo Google Meeting $\complement$, e as aulas gravadas também foram disponibilizadas na sala de aula virtual (assíncrona).

O público-alvo consistiu em acadêmicos em graduação e em cursos de pós-graduação de instituições públicas e privadas.

\section{Resultados}

Após o primeiro caso de infecção por coronavírus registrado no Brasil, o Ministério da Educação (MEC) autorizou a substituição das aulas presenciais pelo modelo remoto para as instituições de ensino superior e, pouco depois, para a educação básica.

A Portaria do MEC № 544, de 16 de junho de 2020. dispõe sobre a substituição das aulas presenciais por aulas em meios digitais, enquanto durar a situação de pandemia do novo coronavírus - Covid-19, e revogou as Portarias MEC no 343, de 17 de março de 2020, no 345, de 19 de março de 2020, e no 473, de 12 de maio de 2020.

As instituições públicas e privadas, não estavam preparadas para atender a demanda de um ensino remoto de qualidade, e logo se constatou o impacto negativo no sistema de educação brasileiro, com a dificuldade no ensino e perda da aprendizagem.

Nesse contexto foi lançado edital PACE Emergencial supra citado, que teve como objetivo geral estimular docentes e discentes da Universidade Federal do Amazonas a se envolverem em ações de extensão durante o período de Ensino Remoto Especial (ERE), referente ao semestre 2020/01.

Além disso, um dos requisitos do edital é que as ações de extensão universitária tivessem como publico alvo a comunidade externa da UFAM.

O curso teve maior número de alunos de instituições privadas, com 59\%. Enquanto os alunos das instituições públicas totalizaram 41\%, conforme figura 1. 
Houve a predominância do sexo feminino na participação do curso com percentual de $59 \%$, enquanto que o sexo masculino foi de $41 \%$. Esse resultado está alinhado à afirmação de Guedes (2008) que comunica:

\begin{abstract}
"O olhar para a trajetória das mulheres com nível universitário consolida a análise de um grupo que manifesta e reflete contradições do próprio processo de mudança nas relações de gênero na sociedade brasileira, no atual momento histórico: ao mesmo tempo que indica sinais expressivos de novos modelos do feminino (menos articulados exclusivamente ao espaço doméstico), também apresenta traços marcantes de uma cultura patriarcal (ainda) presente em diversas esferas da vida social" (GUEDES, 2008).
\end{abstract}

Figura 1 - Tipo de instituição dos participantes do curso

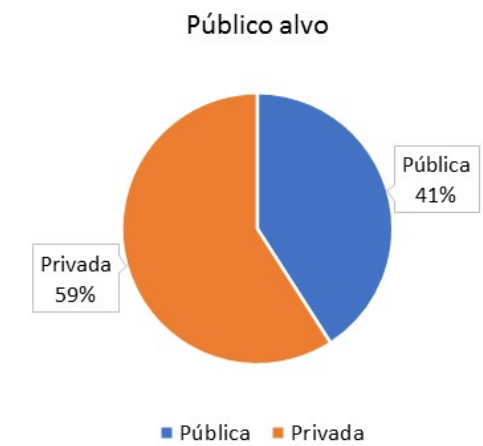

Fonte: Elaboração dos autores
Figura 2 - Participantes do curso, por sexo Sexo dos participantes

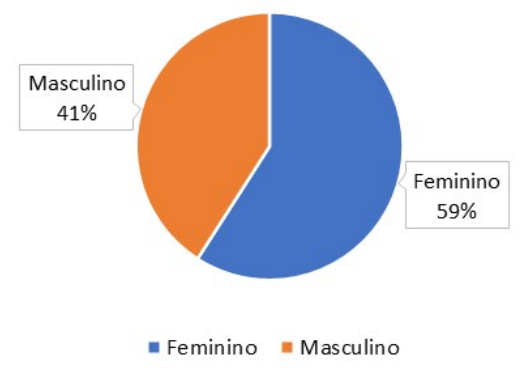

Fonte: Elaboração dos autores

Dos participantes do curso $88 \%$ estavam em graduação e $11 \%$ pertenciam a cursos de pós-graduação (figura 3). Analisando os dados de filiação às instituições, verificou-se que $56 \%$ eram públicas e $44 \%$ privadas, conforme figura 4.

Figura 3 - Nível de formação dos participantes do curso

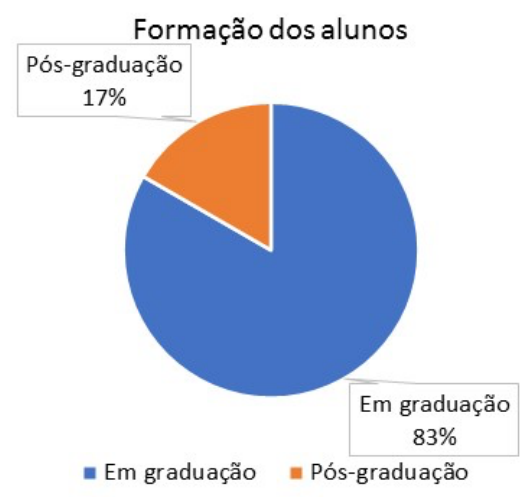

Fonte: Elaboração dos autores
Figura 4 - Filiação às instituições

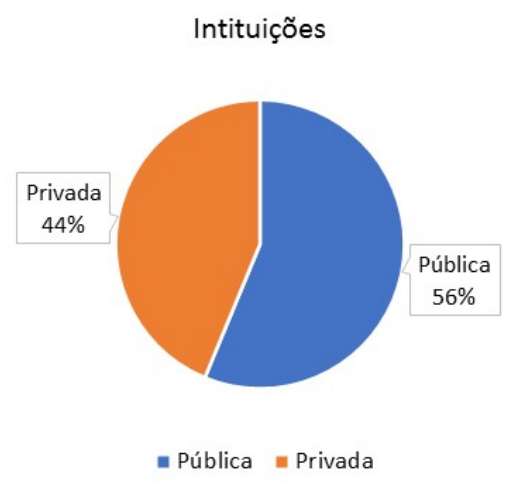

Fonte: Elaboração dos autores

Na figura 5, pode-se observar a distribuição dos alunos em 15 instituição de ensino superior e uma de pesquisa. E verifica-se que 25 alunos estavam matriculados em cursos de graduação da UFAM, 12 da FAMETRO e 8 da FSB. Analisando os dados por região, verificou-se que $81 \%$ pertenciam à Região Norte, $13 \%$ à Região Nordeste e $6 \%$ à Sudeste. Esses dados demonstram a eficácia do ensino a distância, em atender as demandas, independentemente da localização quando se tem o acesso à internet. E as TICS constituem-se em ferramentas fundamentais para o ensino de forma remota síncrona e ou assíncrona. 
Figura 5 - Distribuição de participantes por instituições

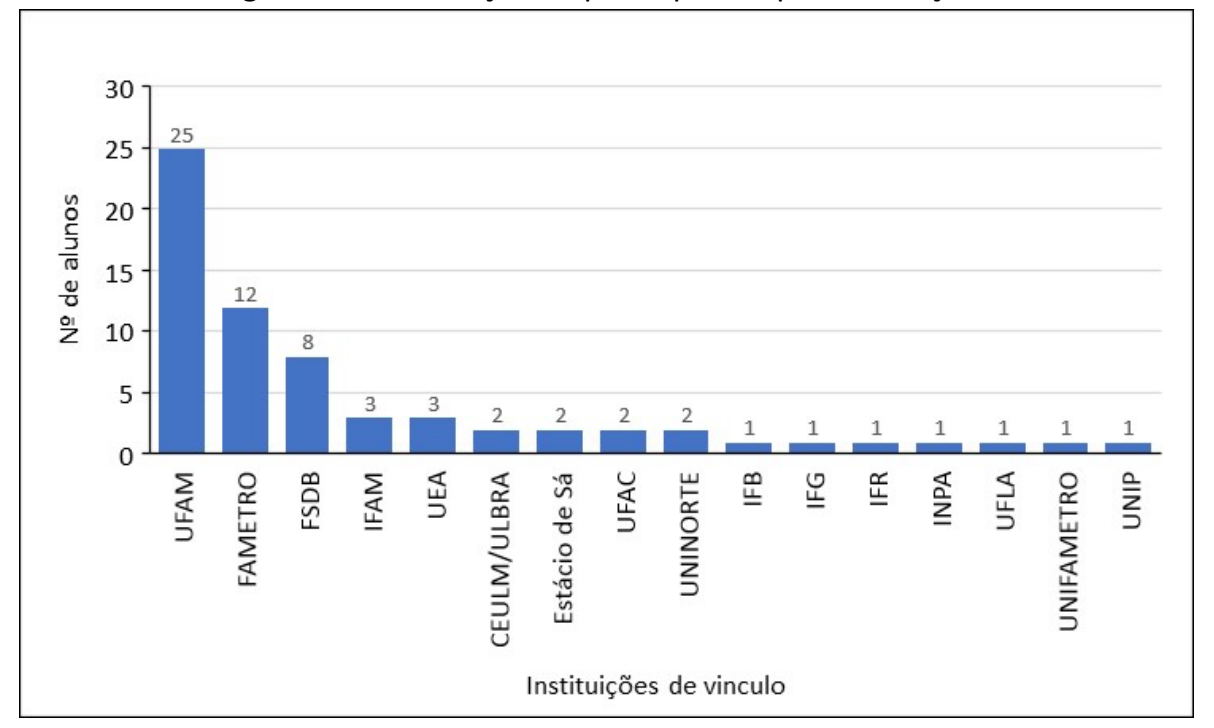

Fonte: Elaboração dos autores

Com a pandemia do coronavírus as Instituições de Ensino Superior (IES), foram impelidas imediatamente a incorporarem as rotinas o ensino remoto e híbrido, como alternativa ao presencial, para isso uma série de medidas foram tomadas como aquisição de plataformas digitais de ensino, investimento em qualificação dos professores para uso das TIC's, alunos recebem chips para acessar internet, etc.

E dada a habilidade da IES em identificar as necessidades de mercado, as tecnologias podem impulsionar cursos de especialização e extensão em nichos em expansão no mercado. Assim, os resultados da pesquisa reforçam a busca pela coerência em termos de estratégia [....]. A isso se somam as tecnologias de informação, que se por um lado o dinamismo das tecnologias sistematicamente lançadas no mercado foi apontado como uma ameaça, dada a dificuldade em se acompanhar o mercado de novos entrantes, que empenham investimentos em tecnologias mais recentes e dos investimentos necessários para acompanhar essas necessidades competitivas, por outro pode representar uma oportunidade (LARA, ROSATTI e JOVETTA, 2016).

Contudo, os desafios enfrentados na ministração do curso foram: instabilidade na internet, que ocorria após uma hora de curso; falta de conhecimento de informática dos alunos, que dificultou a realização dos exercícios; e $36 \%$ não concluíram o curso.

A seguir apresenta-se alguns relatos dos alunos que concluíram o curso:

"Este curso foi muito útil para elaborar meu TCC, pois tinha muitas dúvidas de como proceder na organização dos materiais coletados sobre a minha pesquisa. A última aula me deixou mais segura e confiante para apresentar meu trabalho..." A.C.S.L. (BONATTO, 2021).

"Muito enriquecedor. De extrema importância para qualquer estudante que queira revigorar seus conhecimentos e aprender como produzir um trabalho de conclusão de curso com excelência" P.S. (BONATTO, 2021).

"O curso foi de extrema importância para os alunos. Aulas diretas, bem explicas e material de qualidade..." L.L.S. (BONATTO, 2021). 


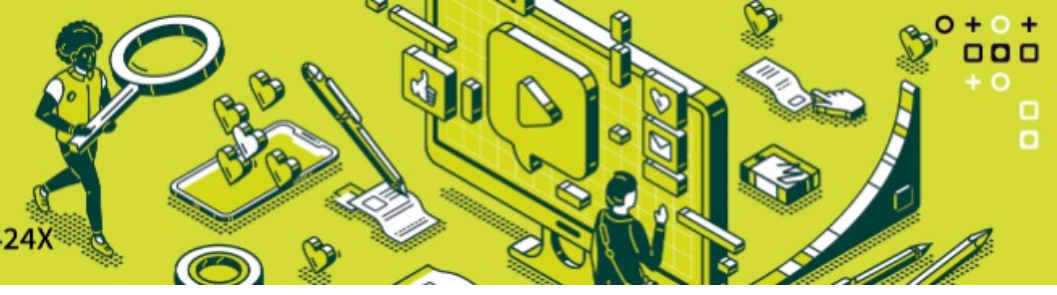

\begin{abstract}
"A experiencia vivida foi muito enriquecedora e fundamental para sanar dúvidas a respeito de formatações, normas da ABNT, e organização do trabalho. As aulas tiveram teoria e prática, facilitando assim, o entendimento, principalmente pela didática utilizada pela professora, despertando interesse na construção de um trabalho" R.S.R.V. (BONATTO, 2021).
\end{abstract}

Os relatos apresentados, demostram que houve satisfação em relação ao curso ministrado (sala virtual, material didático, aulas ministradas), assim como, a contribuição dos conteúdos para elaboração do TCC.

Um estudo sobre orientação de TCC no ensino a distância conduzido por Cartaxo, Mendes, e Perobelli (2008) enfatizam a necessidade da utilização de normas técnicas desde a organização e apresentação do próprio texto até citações e referência; utilizar modelos, inclusive de textos-padrão, para facilitar a organização dos trabalhos dentro das normas estabelecidas para a apresentação, como parágrafos, espaçamentos, recuo, entre outros.

Marconi e Lakatos (2010) afirmam que os trabalhos científicos devem ser elaborados de acordo com normas preestabelecidas e com os fins a que se destinam. Serem inéditos ou originais e contribuírem não só para a ampliação de conhecimentos ou a compreensão de certos problemas, mas também servirem de modelo ou oferecer subsídios para outros trabalhos.

Os alunos reconhecem a importância do professor como mediador no processo de ensino e aprendizagem, por não serem autodidatas, apontaram fatores que dificultam o andamento das aulas remotas como: a qualidade da internet, alunos que utilizam a internet do vizinho, a falta de capacitação dos professores para lidarem com os recursos tecnológicos, a maioria dos alunos sentem dificuldade em manejar bem a tecnologia, falta de concentração nas aulas por não terem um ambiente adequado, as questões emocionais tem desencadeado problemas de ansiedade, o medo no momento de interagir nas aulas online, desenvolvendo estresse dificultando o desempenho da aprendizagem (SILVA, SANTOS e PAULA, 2020).

Com o objetivo de discutir como participantes - aluno orientado e professor orientador - constroem conjuntamente entendimentos acerca do que conta como escrita acadêmica durante uma sessão de orientação e, ainda, como esses entendimentos são elaborados pelo estudante na escrita de um TCC, Petermann e Jung (2020) destacam a importância de compreender a escrita como prática na qual os participantes têm agência ao negociarem intercompreensões a partir de seus lugares sócio-históricos e dos modos culturais de participação em práticas letradas das quais já participaram e que constituem o seu repertório.

Por conseguinte, o conhecimento científico, está alinhado as normas técnicas, desde a elaboração do projeto, execução da pesquisa, e confecção do relatório, tcc, artigo, etc. Todavia, também é indissociável dos nossos lugares sócio-históricos e dos nossos modos culturais.

Miguel, Silveira e Del Maestro (2021) comentam que [...] a extensão comporta-se nessa direção como redes sociais e territórios de significados no quadro da cultura informacional, e demanda a interdisciplinaridade para o estudo dos seus objetos pelo ângulo das práticas sociais de informação, inaugurando novas metodologias para ampliar saberes.

As redes de extensão universitária que atendem as demandas sociais, também fazem a conexão de saberes, ampliando as ações extensionistas. 


\section{Considerações Finais}

Considerando a proposta de ementa do curso proposto na ação de extensão universitária, buscou-se contribuir para uma sociedade mais justa, democratizando o conhecimento, e proporcionado o acesso aos alunos em graduação e pós-graduação de outras instituições de ensino superior.

Os participantes dos cursos estavam matriculados em 15 instituição de ensino superior e uma de pesquisa. Os alunos em graduação totalizaram $83 \%$ e os de pós-graduação, $17 \%$. O sexo feminino foi predominante (59\%). As instituições de ensino superior, que os participantes estavam vinculados, pertenciam as regiões norte ( $81 \%)$, nordeste $(13 \%)$ e sudeste $(6 \%)$. Assim, o ensino remoto associado as TIC's, material didático bom e o acesso à internet, podem contribuir de sobremaneira para continuidade do ensino e aprendizagem, inclusive por meio de ações de extensão universitária.

\section{REFERÊNCIAS}

BONATTO, E.C.S. (2021) Curso teórico-prático para elaboração de Trabalho Conclusão de Curso -TCC. Relatório final. PROPESP/UFAM. 5 p. ilust.

CARTAXO, S.; MENDES, K.; PEROBELLI, R. M. B. Tutoria no ensino a distância na orientação do TCC: estabelecendo procedimentos. Revista Intersaberes. n. 6, p. 177 - 191 | jul-dez (2008). Disponível em: https://www.revistasuninter.com/intersaberes/index.php/revista/article/view/137.Acesso em: 20/10/2021

FURASTÉ, Pedro Augusto. (2012). Normas Técnicas para o Trabalho Científico: Explicitação das Normas da ABNT.- 16. Ed. - Porto Alegre: Dáctilo Plus.

GUEDES, M.C. A presença feminina nos cursos universitários e nas pós-graduações: desconstruindo a idéia da universidade como espaço masculino. História, Ciências, Saúde-Manguinhos [online]. 2008, v. 15, n. suppl [Acessado 29 Outubro 2021], pp. 117-132. Disponível em: <https://doi.org/10.1590/S010459702008000500006>. Epub 03 Jul 2008. ISSN 1678-4758. https://doi.org/10.1590/S0104$\underline{59702008000500006 .}$.

LARA, F. F.; ROSATTI, L. A.; JOVETTA, R.. Análise SWOT de duas instituições de ensino superior no estado de São Paulo: potencialidades para a expansão da educação à distância. Revista Brasileira de Administração Científica, v.7, n.2, p.127-144, 2016. DOI: http://doi.org/10.6008/SPC2179-684X.2016.002.000

MARCONI, M.A.; LAKATOS, E.M. Fundamentos de Metodologia Cientifica. 7. Ed. São Paulo: Atlas, 2010.

MELO, C.B. et. al. A extensão universitária no Brasil e seus desafios durante a pandemia da COVID-19. Research, Society and Development, v. 10, n. 3, e1210312991, 2021 (CC BY 4.0) | ISSN 2525-3409 | DOI: http://dx.doi.org/10.33448/rsd-v10i3.12991

MIGUEL, M.C.; SILVEIRA, R.Z.; DEL MAESTRO, M.L.K. ExtensãouniversitárianoenfrentamentodaCovid-19:a universidade $\mathrm{e}$ (re)configurar de projetos e ações. AtoZ:novaspráticaseminformaçãoeconhecimento,10(1),72-84,jan./abr.2021. Disponível em: https://brapci.inf.br/index.php/res/download/157805. Acesso em: 27/10/2021

PETERMANN, R.; JUNG, N.M. Escrita acadêmica no ensino técnico integrado ao médio: negociações em torno da escrita de um TCC. Forum lingüístic., v. 17 n. 4 (2020). Disponível em: https://periodicos.ufsc.br/index.php/forum/article/view/67912. Acesso em: 20/10/2021.

SILVA, Alba Valeria Vieira da; SANTOS, Helisandrados Reis; PAULA, Luiz Henrique de. (2020) Os desafios enfrentados no processo de ensino e aprendizagem em tempos de pandemia nos cursos de graduação.

Anais. In: VII Congresso Nacional de Educação. Disponível em: https://editorarealize.com.br/editora/anais/conedu/2020/TRABALHO EV140 MD1 SA19 ID4434 14092 020210502.pdf. Acesso em: 10/10/2021.

TRINDADE, A.P.N.T.; BACHUR, J.A.; OLIVEIRA, F.B.O. TCC: um momento obrigatório ou uma oportunidade construída? Revista Triângulo, v. 11 n. 1 (2018). Disponível em: http://seer.uftm.edu.br/revistaeletronica/index.php/revistatriangulo/index, Acesso em: 20/10/2021. 